\title{
'Make Not Your Prisons Your Prisons': Participant-perceived Potential Outcomes of a Shakespeare Focussed Alternative to Juvenile Incarceration in the USA
}

\section{Emotional and Behavioural Difficulties Journal}

Laura Louise Nicklin

\section{Abstract}

For over two decades, there has been a progressive emergence of Shakespeare-focussed, performance-based programmes intended for use as criminal rehabilitation in the USA. Prison based criminal retribution, though historically prevalent, remains controversial. Although it is still used as a common method for rehabilitation, evidence demonstrates that alternative sentences have a consistently more positive impact on reducing rates of recidivism. Some criminal justice organisations and institutions in the United States of America have invested in enabling Shakespeare courses to become supplements or, in some juvenile cases, alternatives to incarceration. In particular, some state judiciary courts have introduced a series of Shakespeare courses to serve as alternative sentences for juvenile crime. The Shakespeare focussed alternative programme considered in this research is celebrating its seventeenth anniversary in 2017. This article considers the specific programme practices and reported outcomes of one now well established, yet widely underreported, Shakespeare-based alternative programme for juveniles in the USA, exploring the juvenile perspectives of the outcomes of activities that are designed for them by adults working in performing arts and/or juvenile criminal services. Key outcomes from participants related specifically to programme content, the selection and use of Shakespeare, skills acquisition and personal development culminating in overall behavioural change.

\section{Introduction}

Throughout history the efficacy of prison as an approach to criminal retribution has been questioned. Though many offenders face incarceration, there is considerable evidence that alternative sentences, such as education, have a greater impact on reoffending (UK Prison Reform Trust 2015). This paper considers one Shakespeare-focussed performance-based juvenile programme created collaboratively by juvenile courts and theatre practitioners as an alternative to incarceration in one US state. There is considerable research demonstrating success for alternative juvenile sentencing focussed on reoffending (Guerin, Otis, and Royse 2013; Curtis 2014; Artello et al. 2015). Juveniles are defined in this text as children aged 11-18.

\section{Approaches to criminal rehabilitation}

Community-service and education-based sentences have been statistically more successful in reducing recidivism than short-term incarceration (Ministry of Justice 2013a). In terms of young offenders, alternative approaches have been established in recent years with both the UK and the USA shifting focus towards non-incarceration. For example, between 2012 and 2013 the prison population fell in England and Wales, and this reduction linked to a reduced use of incarceration for juveniles (Ministry of Justice 2013a). This does not mean that there were fewer young offenders convicted, but that more alternative sentences were administered.

Findings reported here highlight positive outcomes of one such alternative sentence for US juvenile offenders, providing Shakespeare-focussed court-mandated courses to juveniles involved in antisocial or criminal behaviour. The perceived value of a collaborative and reflective approach 
grounded in Shakespeare and theatre is explored in this paper to highlight the potential rehabilitative value, and therefore impact on repeat offending, this could have. The findings of this paper surround the participant-perceived impact of the approach including skills acquisition such as self-expression, self-confidence and conflict resolution, social interaction including empathy, trust and communication and experiences of commitment and achievement.

\section{Education-based interventions}

For almost two decades, the programme considered here has offered a practical approach to juvenile rehabilitation promoting an educational rather than punitive provision. This is an example of one pioneering education-based initiative that permits juveniles to live an integrated life in their own communities, whilst working to modify behaviours. This places juvenile rehabilitation within direct context of society at large, rather than artificial prison environments, recurrently critiqued as widening divisions between offenders and society (Peacock and Theron 2007). Such interventions do not have to come post offending behaviour, where children with emotional and behavioural difficulties could engage in this type of intervention before they reach the point of criminality. The same issues can be explored to support children and potentially prevent them from ever being involved in the criminal justice system.

Since 2013, the UK public debate has surrounded government proposals to introduce educationbased interventions into criminal rehabilitation. There is a considerable divide in public perception between those who consider education programmes to be 'treats' rather than the 'treatments' that they are intended to be. This conclusion is here drawn from online commentary surrounding the proposal of such initiatives as the 'Earned Release Scheme'1 (Ministry of Justice 2015; Conservative Party 2015). Public support is arguably essential for alternative sentencing ideas to become a reality, due to active political agendas surrounding the issue (Roberts 2011; Berk and Rossi 1997). One recurrent feature of the treat-versus-treatment debate questions the economic value of the programmes, even though the UK Government spend over $\mathrm{f} 247$ million on youth detention, and costs of imprisoning a youth offender are between $£ 100,000$ and $£ 200,000$ yearly (Grayling 2014). This is an interesting objection when pitched against the cost of courses that may prevent future incarceration, which could be considerably lower, taking into account the current $83 \%$ juvenile reoffending rate. Where reoffending costs between $£ 9$ billion and $£ 11$ billion per year (Coates 2016), associated reductions in reoffending may mean that educational and vocational programmes could potentially save over $£ 50,000$ per prisoner (Marsh 2008). Dame Sally Coates conducted the 2016 review of the UK prison education, and highlighted differences between prison as punishment and prison for punishment, highlighting the investment return value for societal investment in education (Coates 2016). Economic arguments are recurrently linked with thinking that offenders are unworthy of investment, however in the US context, introducing community sentences from the 1970 s onwards was grounded in cost-effective and rehabilitative motivations (Wood 2011). To dismiss rehabilitative arguments entirely is to dehumanise offenders, where they are consistently described in derogatory terms such as 'thug' rather than what they actually are, children. Though it may be argued that the two descriptions are not mutually exclusive, stereotypes should not serve to define a person any more than other stereotypes, for example racial or gender-based, are permitted to do. Regardless of this, children who have been involved in such behaviour are socially constructed into two subcategories; wayward youths needing intervention or underserving delinquents. Though this perception exists, there is active support for child rehabilitation (Moon et al. 2000).

Though at the point of project introduction there was considerable public debate, community sentences remain a popular choice in the USA (Wood 2011). The wider study these data derive from investigates how Shakespeare is currently used in criminal rehabilitation with juvenile and adult 
offenders in the USA to explore potential alternative approaches for the UK context. Shakespearespecific alternative juvenile sentencing is exclusive to the USA, therefore the US criminal justice system and educational contexts must both be considered in contextualising and exploring the applications of this research.

\section{Context}

\section{Statistical outcomes of existing practice}

Where attitudes are divided surrounding prison purpose between punitive and rehabilitative models of sentencing, it is important to consider the outputs of UK prisons, in their existing form. In the UK, 45\% of the adult prisoners released in 2010 reoffended by 2015, a third of which did so in the first 6 months (Ministry of Justice 2015). The USA national recidivism is no better averaging $70 \%$. In addition, $68 \%$ of the offenders under the age of 18 released in 2012 reoffended within 1 year of release (Ministry of Justice 2015). Prison costs the British economy up to $f 13$ billion per year (National Audit Office 2010) and statistics continue to demonstrate high reoffending rates. Yet, prison continues to heavily feature in the British justice system, with prison being recurrently applied for short, under 1 year sentences.

Statistically, community-based sentences are more effective in reducing reoffending than short sentences (Ministry of Justice 2013b), and research demonstrates that prisoners report little value in, or fear of, multiple short sentences in prison beyond incapacitation and segregation (Armstrong and Weaver 2013). Short prison sentences have even become a recurrent experience for many prisoners, offering little more than temporary isolation (Armstrong and Weaver 2013). Education and training have however been identified as a critical factor in successful criminal rehabilitation (Hayes and Blunt 2011; Batiuk, Moke, and Rountree 1997).

Adulthood can be a turbulent complex transition experienced by all children. Both the British and the US schooling systems serve to make that transition smoother through qualification and pastoral support. For juvenile offenders, incarceration can often leave them 'lagging behind their cohort' in terms of these critical factors (Uggen and Wakefield 2005). Approaches grounded in applied theatre, as the programme here considered is, are one internationally thriving educational intervention style. Though obscure in definitions it is broadly understood to be an umbrella term for the range of theatre activities which facilitate intentional connections to social issues (Prentki and Preston 2013). Spearheaded by Augusto Boal, and grounded in the educational theories of Paulo Friere, this approach has come to popularity since the late twentieth century, though there are earlier examples of this. This style of practice is often involved in the context of youth either at-risk or involved in criminal behaviour based on the belief that it can impact the way a particular individual or group interacts with the wider world (Prentki and Preston 2013; Nicholson 2014).

Educational and community sentences in general foster opportunities to overcome the divisions and deficits that educational disengagement can cause both between members of a single community or cohort, and between individuals and society at large and applied theatre offers one tested route through which this holds potential. By providing rehabilitative activity within the context of real society, rather than marginalising artificial detention facilities participants in the Shakespeare programme are able to maintain their physiological connection to their communities, whilst also working to integrate and develop rapport between participants and society at large.

Almost 50\% of the 2015 UK prison entrants received short sentences. Though statistics demonstrate short-term sentences to be a largely unsuccessful approach to criminal rehabilitation, for adult offenders prison is still a heavily utilised approach to tackling offending. For juveniles, a shift in focus 
is emerging. The reported educational background of juvenile offenders is poor with many histories of low attainment and school exclusion (Prison Reform Trust 2015). In addition, $47 \%$ of the prisoners in 2012 held no qualifications (Ministry of Justice 2012) and 42\% had been excluded from formal schooling. To compound this, the UK Office for Standards in Education (Ofsted) found that over 50\% of the education services in prisons they inspected in 2014 were deemed inadequate or requiring improvement (Ofsted 2014). The UK proposals from 2016 focus on more education-focussed approaches to incarceration. This model calls for the role of prison staff to be more closely linked to education, via practical training approaches similar to the 'Teach First' route for teacher training (James 2016). Commissioned to review prison education for the Conservative Government in 2015, Dame Sally Coates recommended this approach, focussing on accountability, education and empathy with the intention of an overhaul of not only prisons themselves but also attitudes held by and towards offenders (Coates 2016).

Though juvenile education and alternative sentencing has been prioritised, there are still incarcerated youth, who have been classified as some of the most vulnerable children in the UK (Prison Reform Trust 2015). Since 2015, the Conservative Government, building on initial proposals under the 2010-2015 UK Coalition, have claimed punishment is important for juvenile offenders but education is the cure (Clegg et al 2014). Ex-Secretary of State Chris Grayling vowed to place education at the heart of criminal rehabilitation, an approach which ex-secretary of state for education and ex-secretary of state for justice Michael Gove continued (Travis 2015; Gove 2015). Though many prisons hold education provisions, standards remain inconsistent.

Internationally, there are programmes of juvenile rehabilitation to consider that focus on offering offenders education for personal development rather than punitive punishment. These approaches work to foster a better reintegration of juvenile offenders into mainstream society and break the cycle of them underachieving in relation to their peers (Uggen and Wakefield 2005). Originating in the US context, Geese Theatre UK, for example, have engaged in substantial work combining theatre and rehabilitation since 1987, proposing applied theatre as a medium to 'explore behaviour' and 'contemplate the possibility for change' (Watson 2013). Grounded in the applied theatre methodology Geese work to create drama that accurately mirrors the victims' world, creating opportunities for self-recognition and reconnection to society at large. The intention is to offer a rehabilitative approach to criminal rehabilitation with an active intention to identify, understand and transform negative behaviours.

This less punitive model is exemplified by the programme considered in this research paper that for almost two decades has been deemed a successful approach by court officials, past participants and stakeholders in the projects, with the programme receiving prestigious awards for their achievements and one state juvenile court continuing to endorse this programme as a suitable alternative sentence. This programme works with juveniles involved in non-violent crime, who are court sentenced to attend a compulsory Shakespeare programmes as a direct alternative to traditional incarceration. They offer a 10-week court-mandated course for juvenile offenders, through which they are required to engage in compulsory Shakespeare-focussed activities for skills development and issue exploration. Removing focus from final performance quality, these programmes seek to enhance skills such as commitment and communication for social reintegration.

It may be logically presumed that through this process participants are expected to be 'fixed'. Crucially practitioners state the intention as not to 'fix' participants, but equip them with skills to fix themselves. This is the key distinction critics misunderstand, often claiming theatre programmes to be soft alternatives and not punishment. As pre-pilot research, I conducted a discourse analysis of public and media responses to the initial introduction of these programmes and discovered that 
responses were not only $65.1 \%$ opposing the programmes introduction, but $21 \%$ of this negative response surrounded the notion of offenders as 'unworthy' or a 'waste' with programmes seen as 'rewards' rather than 'punishments' or 'treatments'. The difficulty of the process as a difficult educative experience and the degrees of psychological engagement required are overlooked. Participants are encouraged through Shakespeare's characters, situations and texts to reflect on their own lives. Such reflective practice is recurrently cited in drama-based approaches to therapy including psychodrama (Baim 2004) and drama therapy (Landy 1994; Jones 2006). This practice of self-reflection and community impact brings potentially uncomfortable but vital lenses of understanding. To ascertain the programme potential, participant perceptions must be considered. This therefore is the focus of this paper, exploring the potential benefits or positive outcomes one Shakespeare-focussed sentence may offer juvenile offenders.

\section{Method}

This paper presents an outline of specific practices involved in, and a thematic analysis of participant-reported benefits of, one Shakespeare-focussed alternative juvenile sentence. It also draws on direct researcher experience, and feedback from practitioners and participants given during and post participation in the Shakespeare programme.

\section{Research questions}

There were four key research questions for exploration:

(1) What is involved in a Shakespeare programme?

(2) How is it delivered?

(3) What are the intended and perceived outcomes of and for participants?

(4) Why specifically Shakespeare?

The data selected for quotation here offered best examples to reinforce points taken from analysis of the whole data set. All data relating to this juvenile programme were considered and included in constructing the findings of this research study.

\section{Data collection}

Firstly, the researcher actively participated in 12 sessions of the 2015 programme, producing research diaries detailing the specific practices, and participant engagement in the moment. Excerpts of such data are included within thematic consideration of participant input. Secondly, participant interviews and archival participant feedback were collected to gain wide-reaching participant-reported outcomes. This paper focusses on positive programme outcomes, not claiming that these programmes provide perfect solutions, but rather highlight the rehabilitative potential this approach could have for juveniles.

\section{Sample and demographic}

The sample was taken by convenience from the only active group at the time of data collection and included active participant interviews with co-ed juvenile participants, archival formal feedback given by participants on project completion and ethnographic data collected by the researcher's active engagement with the group in May 2015. Though the active participant group available for interview was small consisting of 6 participants involved in the participant observation, an additional 
56 participant feedback forms were collected from programme archives to enhance the validity and consistency of the research findings.

All programme participants were based in an area of low socio-economic status. Though specifics about the individual children could not be known due to ethical restrictions, all participants had been involved in non-violent, anti-social, negative behavioural or criminal action. The background of the students had no bearing on the activities provided and programme requirements.

Participants were sentenced to the programmes by a typical juvenile sentencing court judgment. The programme was delivered by a professional Shakespeare-specific theatre company that engage heavily in educational outreach. This company was responsible for project delivery with the backing of the juvenile court for pastoral and administrative support.

\section{Measure}

This paper details reported outcomes taken from participating voices in the programme. The main focus is the participant voice, as the voices of pupil communities facing educational and behavioural difficulties are notoriously overlooked, due to the challenging nature of this endeavour. This is just one of the many barriers preventing marginalised youth voices being heard in a society where adults speak for them (Sellman 2009; Doherty 1997). It is vital to consider outcomes through this lens as the programme does not seek to change the children by speaking for them, but rather equip them to express themselves to work towards change.

Though there are many diverse practitioner reasons reported for the selection and use of Shakespeare, the voice of participants is essential to clarify and correlate outcomes reported by the participants affected by this approach. Two overarching themes emerged in relation to participantreported programme outcomes: programme practices including Shakespeare, and personal and skills development. All reported outcomes were categorised accordingly. Voice and agency can be controversial issues in their definition and relationship with applied theatre practice, as what organisations say about participant leadership and what they actually produce can be two different things (Etherton 2009.) For example, agencies conducting applied theatre work claim to want children to drive 'their' projects, however this is often in adherence with the agenda of the delivering agency (Etherton and Prentki 2006). For this research, whether this was being achieved was strong motivation for participant voices as they could articulate the balance between participant driving and agency intention.

\section{Ethical restrictions}

Due to the nature of communities involved all identifying features must remain vague and anonymised. This paper is not to serve as an advertisement for the programme discussed, but rather demonstrate potential outcomes of a Shakespeare-focussed applied theatre approach to juvenile rehabilitation. Any resemblance to participants within this text is purely coincidental, and all participants discussed have been adapted to ensure protection.

\section{Findings}

The programme practices are outlined here to contextualise participant-identified outcomes, including facilitator motivations for using Shakespeare. Outcomes identified from programme participants could be categorised into one of two broad themes; personal and skills development and impact of specific programme practices, including the selection and use of Shakespeare, and participant and practitioner-perceived benefits of this. The findings of this project presented in this article mainly advocate the positive potential of this programme as although the approaches are 
interrogated throughout the research project, the intention of this article is to explore the potential benefits this approach could offer in the UK context.

Programme practices and the use of Shakespeare

\section{Specific practices}

The sentence requires juveniles to engage in a programme of rehabilitation reflecting an appliedtheatre methodology not dissimilar to the work of Geese theatre UK or TIPP (Brookes and Mountford 2002; Blacker, Watson, and Beech 2008; Balfour 2004) .On the programme considered here however, this approach is coupled with Shakespeare, focussing on the personal development of participants through Shakespeare-based activities.Participants are involved in 10 weeks of activity over weekdays from school finish until early evening, before returning home. This programme allows participants to live normal lives, attend schools and sleep in their usual environment whilst receiving rehabilitative education. The programme uses Shakespeare to explore issues, build skills and enhance confidence to encourage participants to critically evaluate life choices.

Every workshop is bookended by a 'check-in' and 'reinforcement' session. At session commencement all participants must engage in 'check-in' whereby they, at developing levels of depth, must share how they feel. They can choose the depth of detail they share under the understanding that they may speak freely without censure, interruption or repercussion. The programme intends to scaffold participants to progress from basic statements of emotions to deeper discussions. As the programme continues participants claim to develop confidence and trust in their group, enabling them to share personal issues and consider how the programme impacts their dayto-day lives. For many this task is initially unpopular, and an opportunity to attempt disengagement. When asked why she didn't want to check-in at interview, one participant shared:

"I don't talk about things. It's hard and like I don't want people thinking I'm dumb or whatever because I'm upset or mad about something."

This individual initially refused to participate but regardless of how long it takes all participants must check-in before the workshop continues. Towards the end of the programme, check-in participation became easier, with all participants sharing more information with little resistance. One young person interviewed shared a more positive perception of this practice:

"Check-in is my favourite, because if I'm mad at my day or whatever or I got in trouble I can talk about it here and I'm not getting in trouble all over again."

For some participants, honesty without repercussion is both unfamiliar and emancipatory.

Each session concluded with 'reinforcement' whereby participants contributed what they have learned or achieved. Each group member was encouraged to reflect on the actions of the day, both offering and receiving encouragement to reinforce positive behaviours. Examples of reinforcements ranged from

"I reinforce that you guys are nice to me"

to more considered claims such as;

"I reinforce that I get why the queen gets mad now, I get it because I wouldn't want to be treated like that and you just shouldn't do that. I get mad at my family, and I do mean things and get in trouble, that's not cool is it." 
The above is a powerful example of detailed reinforcement and the critical thinking and reflective application to real-life experiences the programme hopes to foster. A multitude of highly emotional check-ins and reinforcements followed throughout my time in the group and, for many this caused discomfort or frustration. Though potentially frustrating, it was crucial that individuals were pushed to contribute, enabling them to reach beyond existing comfort zones.

Participants engage in Shakespeare-grounded games and activities. They are required to act, make decisions, interact with and trust others and interpret Shakespeare. Texts used are not simplified, but offer original language with book-based resources, and practitioners to aid with interpretation. Shakespeare is stigmatised as difficult or for intelligent people (Gilmour 2015; Burdett 2003). Unusually for modern education, no internet resources were available and they were not permitted to ask for answers placing the responsibility of interpreting texts and developing meaning on participants. Although book-based resources were provided, participants did not have to get the 'right' meaning, instead interpreting them relevant to their own life experiences. This ensures participants develop their own personal interpretations to best suit their own needs or experiences and crucially take success in doing this for themselves. Though not without critique, world-renowned Shakespeare education departments and scholars have supported movements promote young people taking ownership of Shakespeare, including the RSC who, through their 'Stand Up For Shakespeare' movement (The Royal Shakespeare Company 2008), encourage participants to 'make their own connections, discoveries and journeys' and 'to make social and personal sense of the language' (Neelands and O'Hanlon 2011). Shakespeare's language, though frequently identified to be a barrier for children, according to Cook (2000) and Winston (2015) can attract them if presented in such a way that a literal translation is of little significance compared to potential personal, ambiguous and creative interpretations.

This practice in relation to the Shakespeare rehabilitation programme includes valuing all participant contributions and ideas, not telling them what to think, thereby developing their confidence to share ideas. For some the greatest benefit is feeling able to speak or express themselves. As one past participant shared:

"It showed me not to be shy while in front of a lot of other people and to be myself in front of a lot of people I didn't know"

For others, being able to not only speak out, but also to apply their ideas and choices to the overall performance was important. If participants interpreted Prospero as a caring father or control freak, this was at their discretion and they were permitted authority. Their opinions were valued and given attention regardless of simplicity or fantasticality. This is deemed a crucial experience both for the participant sharing, and the surrounding group. At times suggestions are made that are unusual. For example, discussion about the mechanicals from A Midsummer Night's Dream involved participants sharing elements that they liked and ideas for their peers to develop. One quieter participant, playing the Lion, had their turn to speak. Amidst a discussion of scene positions, she shared:

"So I have a tail, maybe I could come on and be like tail whip attack and like whip my tail. I like my tail."

Though out of context, and initially amusing to her peers rather than dismissing the suggestion, practitioners pursued this idea. Though seemingly irrelevant to the scene, the participant's idea was included, giving her the opportunity to make decisions. This participant reported feeling listened to:

"It's cool that they listen to you here" 
She felt that her contribution was worthwhile. This also demonstrates a positive example of appropriate social interaction. The programme process is focussed on giving participants food for thought and options to identify best approaches to life situations, with a key focus on developing communication and positive interactions.

The participants involved in this programme have their personal image and their own fears surrounding being considered 'uncool'. The programme aims to foster an ensemble, embracing individual differences. Participant feedback outlined 'friendship', 'trust', 'care' and 'support' as favoured outcomes. Participants in small groups and as a collective worked through their own issues to support each other. The programme constructed an experience that served as a positive memory that participants might draw on and learn from in future situations.

The key skills of empathy, confidence and self-expression are at the core of both intended and perceived outcomes. Participants recurrently place high value on being listened to, supported, and able to speak. They report being empowered to make choices and communicate to overcome issues affecting their lives beyond the programme. These findings relate to the activities and motivations of the programme and are also essential when considering the specific value of Shakespeare within this.

\section{The selection and impact of Shakespeare}

A variety of different reasons is cited by practitioners surrounding the selection of Shakespeare in criminal rehabilitation, and there are recurrent claims which feed into programme practices. Motivations include Shakespeare's character range, with almost every type of person argued to be discoverable in his texts, the range and applicability of the scenarios and finally the fact that for most participants, Shakespeare's works are foreign. Arguably, the latter could have implications for the applicability of this practice to the UK juveniles as Shakespeare is heavily embedded within the national curriculum for English, and even with increasing disapplication of the curriculum in academies, Shakespeare is culturally embedded. However, initial barriers surrounding language and translation in theory still apply, particularly where juvenile offenders are statistically likely to have low literacy levels (Stephenson 2009; Farrington 1999). In addition, regardless of Shakespeare's place within the curriculum, UK children disengaged from education may be equally unfamiliar with Shakespeare, potentially correlating with fragmented curriculum engagement (Bielby et al. 2012).

The international perception of Shakespeare as difficult and for intelligent people cannot be overlooked. There is a threefold impact of this perception on the demographic of participants involved in this project. Firstly, on a personal level to feel clever or successful at something academic is foreign for many participants, yet participants report feeling smart when they can engage with Shakespeare.

Five out of six interviewee's identified Shakespeare as 'tough' or 'difficult' with all of them making reference to Shakespeare's language. Many participants throughout the programme his-tory have identified expectations of language difficulties. One 2015 participant shared:

"I have to take the time to work out what he's saying. With the books, I get there but I knew it would be tough"

echoed by another:

"I saw it and was like what is this guy speaking about but it's cool cause I get what he means and I can get my character. Beatrice is like being mean but funny or like she likes him or whatever but they like to be fake mean. It's their thing, I like that I get that." 
Language has consistently been identified as a potential barrier to engagement; however, participants recurrently highlight overcoming this as an achievement to be 'proud of', with some adopting Shakespeare's language into their everyday dialect. One participant adopted 'Exuberating' into their dialect, and another boasted experiences of performing her text to others and explaining its meaning. Participants also report feeling smart when they understand Shakespeare, because Shakespeare is for 'smart people'. One participant gave the feedback that they had learned 'not to knock something before you try it', and another expressed their favourite part of the programme as performing Shakespeare, something they never thought they could do.

Feeling proud and intelligent has internal and external potential for personal development. Their community, used to seeing them engage with negative behaviours, may hold low expectations of participants. However, through the programme participants are able to demonstrate their capabilities beyond convictions. One participant considered this:

"It's weird because I told my mom not to come see it or whatever but she says nothing will stop her and she wants to see me up there doing this stuff. And I kind of like that, that she thinks I'm going to do great and she can see that I can do this stuff."

As soon as children engage in criminal activity they are frequently liable to be referred to under derogatory nouns. This is frequently linked to the low age of criminal responsibility wherein the UK children are criminally accountable from 10 years old and in the USA, though states vary, the average age of criminal responsibility is 7 . The assumption that just because the offenders are children they are not accountable is problematic, however as is demoting them from their status as children.

Programme practitioners actively fight against labelling, not to downplay the severity of behaviours but to restore a sense of humanity. Not labelling them as 'risky' or 'difficult', but rather 'capable'. One practitioner explained:

"Regardless of what they did, they're kids on a positive programme. Everyone has their problems sure I do, but labelling them just makes them feel like they are limited by that thing. They're not here for that, they're here to see they can be just as good as any other kid."

This approach seeks not to trivialise past behaviours, but progress towards learning from them. By preparing participants to perform to the community they have opportunities to demonstrate to the public unexpected capabilities. By demonstrating that they can achieve, perform and understand Shakespeare, and offer valuable and insightful contributions, they are offered a fresh chance to change perceptions. The scaffolding the project provides is consistently highlighted by participants as the sole reason they feel able to do this. Rather than seeing themselves and being seen as incapable of achieving, or assuming something is beyond their capabilities, these participants have the opportunity to re-evaluate themselves and project a new image through positive action and the implications of Shakespeare's prestige.

Shakespeare is maintained as the primary subject matter embedded in activities. Most participants had never experienced Shakespeare, limiting many to assuming Shakespeare is 'hard' or 'boring'. A combination of these ideas was common in participant expectations of the programme, and some initially perceived that they were being sentenced to Shakespeare because it is so difficult or dull, an interesting notion, though this could not be further from true intentions. The terminology of 'boring' or 'tough' was recurrently used by existing and past participants to describe assumptions and 
expectations, including their surprise when they discovered something interesting or entertaining through the project. One participant shared:

"I thought Shakespeare was boring ... but this stuff's ok."

echoing another who asked;

"Can you believe that Shakespeare is funny? He actually had us all laughing. I wouldn't have believed that but he is. Especially when there's that bit where Greg takes Charlie's words and acts all girly and stuff."

That comment was in relation to Much Ado About Nothing in a sparring of words between Beatrice and Benedick. Comedy is a recurrent participant favourite and also material they feel most comfortable applying their ideas to. Participants consistently claim enjoyment of this specific genre, regardless of the fact that a diverse range of genres were covered within their performance. The 2015 performance combined history, comedy and tragedy, relevant to individual participant interests and needs. Although a range of characters and genres was included, all participants of the 2015 cohort particularly hailed the mechanicals in act 5 of A Midsummer Night's Dream, which was performed as a whole group.

Though participant enjoyment is not essential it is desirable and although programme attendance is as a result of criminal sentencing, it is crucial to note this work is rehabilitative rather than punitive. In turn the potential enjoyment participants may experience has attracted some negative public attention. However, results continually demonstrate more potentially successful outcomes than publically popular punitive approaches. The difficulty in being able to track participants post participation must be noted also. Because participants are juvenile criminals their records are sealed when they reach adulthood and receive a virtually clean slate. Yet, through an excellent relationship between the programme, sentencing courts and appropriate agencies, and the willingness of some participants to remain in contact, it can be shown that this approach can provide a successful approach to rehabilitation, that also just happens to be enjoyable.

By making the experience productive and enjoyable, practitioners argue that the participant group becomes willing, open to engagement and involved. This is in contrast to early stages of the programme where I witnessed new attendees being defensive in the expectation that they will be facing something they will not enjoy, consequently only choosing to engage and complete tasks to the barest minimum. This is a fear associated with the potential introduction of the UK Earned Release Scheme (Conservative Party 2015) which calls for an academic examination enabling prison release. In theory the introduction of an educational route to rehabilitation brings with it an overwhelming evidence bank of support. However, by introducing an examination to conclude it, the end product is prioritised, not the rehabilitative processes undertaken. Consequently, much like the case of any examination, one may be able to utilise and regurgitate the required information without the ability to apply or contextualise it, or even the intention to put it into practice.

A closer focus on experiential engagement offers different and more personal incentives for completion. Adult prison Shakespeare programmes operating under a similar purpose in the USA also follow the non-examination methodology undertaking a process rather than proof model. They do not provide incentives such as early release or free food, meaning that the only outcomes or incentives for participation are personal development. Though participation in the juvenile project discussed here is mandatory, success levels are determined by the individual.

Personal and skills development 
Each participant has emotional or behavioural issues, skills limitations and strengths as in any community. They shared self-confidence issues, a lack of focus and commitment, educational disillusionment and negative social groups. The first phase of skill development is focussed upon the self, with the project aiming to develop self-confidence and self-expression. Secondly, the project offers a broader scaffolding opportunity to transform negative attitudes towards commitment, developing a fresh focus and opening a plethora of opportunities for achievement.

\section{Focus, commitment and achievement}

It is common for participants to have a negative educational history, and report disillusionment of an education system that they felt prioritised the teachers voice, and the voices of 'smart kids', leaving them devalued and uncommitted to learning. Several felt it relevant to share their willingness to 'say no' or 'skip class' in their school environments. An adult reported one participant too unwell to attend, shortly before he was tracked via ankle bracelet to a local fast-food restaurant. This is a powerful anecdote when contextualised, as even when a court has ordered participation, and the participant is instantly locatable, the participant still attempted avoidance. Some do not complete the programme, though practitioners endeavour to avoid exclusion. Participants have been assiduous in attempting to be excluded from the programme including extreme approaches ranging from truancy to urinating in a fellow participant's drinking water and shoes, the latter offence resulting in serious disciplinary action and eventual removal of some participants. Removal from a court-sentenced programme is difficult and undesirable, therefore practitioners work to avoid this where possible, working with the court to find appropriate solutions. For example, when a participant used expletive language towards a facilitator, rather than rewarding them with exclusion, an agreement was made with the court that a judge would 'read them the riot act and then return them'. Consequences were therefore administered without rewarding the desired get out of Shakespeare free pass.

Many participants share a sense of disregard for commitment, rules and responsibility. Throughout the history of the project participants and practitioners alike have endorsed a crucial outcome of the project to be the power of actually committing to and completing something positive for these children. One practitioner explained:

"they may initially resist but with the encouragement we offer they do allow themselves to get into ideas and start working together. We hope to teach them skills not only to serve out their project, but life skills furthering commitment and holding down a job. These kids have to learn this, and to let people help them."

Commitment and completion lie at the heart of the programme rationale. Practitioners are to ensure whole group completion, fostering achievement, success and pride. To be proud of a positive activity is not only reported as 'new' or 'weird' by participants. This new experience could leave them with a positive impression which could serve to encourage positive activities in future. One participant explained this as a surprise to them halfway through the programmes:

"I guess I didn't know I would care about this, like I actually want to do it right and I want it to be good. Ask anybody, that's not like me to care about some kind of project or whatever but I do. I want people to see it and think yeah, that was great"

Though initially participants find it easy to disrupt or disengage from the required tasks, I witnessed a shifting attitude towards collective commitment. Successful completion is compulsory for all members, and this is supposed to only happen as a whole group, where all sessions must be attended and participants know that the sessions only commence when all are in attendance, or 
only end after the last person has reflected on the day. This has meant that a person has refused participation for 20 minutes before cooperating for group benefit.

In the initial phases of the programme, participants received peer praise for engaging in disruption, not uncommon for these groups according to experienced practitioners. However, by the midpoint a different reinforcement could be witnessed. The group began to self-police, praising good behaviour and discouraging disruption. This collective commitment operates on a stronger level than a set of rules demanding it. Participants began to mentor peers, support and praise positive interaction and it then became unacceptable and socially destructive to cause disruption the group. This course scaffolds a site through which this can be achieved, thus equipping participants with relevant skills in commitment and focus by giving them a powerful reference point of how commitment and positive community can yield pride and success for these participants.

\section{Self-confidence, personal expression and voice}

The group of participants involved in the 2015 programme varied in confidence but all expressed a common fear of public speaking. In the initial phases, participants rushed lines if required to read, attempted to decline input or participation, and frequently precluded their ideas with 'this is stupid but ...' or 'I don't really care but you could ...' There was a clear sense of not wanting to seem uncool, wrong, or too invested in the project, which turned into wanting to show how heavily invested they were by the end. The programme practices as described operate to foster development of confidence in expression starting in small activities moving towards greater responsibilities and more personal engagements. This included placing heavy value on individual ideas not being overlooked or ignored and participants being consistently praised for their input, regardless of the suggestion. Applied theatre methodology indirectly underpins the group's practice style, placing focus on the journey to completion, the lessons learned and process of development, making the completion of the final performance a concluding milestone for participants, rather than an event by which quality indicates success.

During interview, all participants reported increased confidence and self-belief. One participant that had attempted non-attendance several times before getting more involved was asked 'Have you taken anything away from the programme so far?' She shared:

"So, this thing happened today. I did a makeup presentation teaching my class Spanish. I usually say no to getting up or I like just do a bit or whatever but I did the whole thing and got my first good grade in a long time. My teacher made a real big deal ... I see kids who are going to be able to make speeches at graduation. Do you think maybe I could do that?"

This self-belief is a profound change recurrently seen in participants and this is not a one-off example. Yearly there is consistent participant and stakeholder feedback reiterating this message. Over $50 \%$ of the participant feedback forms also shared their favourite outcomes as feeling 'brave' or 'confident' and the sense of disbelief that they had been physically able to appear on stage in front of an audience and not only perform but also demonstrate an understanding of their actions and share that with other people who wanted to hear what they had to say. The active participants in 2015 were working towards their imminent performance when I left them; however, they had peer performed multiple times by this point and been given a plethora of opportunities to ask questions, offer guidance and make creative inputs.

Personal autonomy within the project requirements was a key principle in practice. Participants were offered full choice in their line delivery, character presentation, costumes and props. Though, as identified earlier, there are debates surrounding how much participants in applied theatre 
programmes really have true autonomy over their learning and engagement, the extent to which this is attempted in the Shakespeare programmes is recurrently highlighted as a positive factor by practitioners and participants. Participant input was always shown to be considered and supported where possible with nothing reasonable being ignored or disregarded. For example, the 2015 group knew that the mechanicals scene from a Midsummer Night's Dream was supposed to be comical, and they had tried the death scene with both a giant oversized novelty sword and tiny retractable dagger. The pair playing Pyramus and Thisbe had a Wolverine retractable toy claw that they offered as an alternative weapon, justifying the comedy this could bring if Thisbe couldn't lift the sword so instead resorted to metal claws in her suicide. The group loved this idea, and wanted to incorporate this, seeing no resistance from facilitators. I discussed this with the facilitators, and one explained:

"This means they are going home and thinking about what they have done here, how they can work on it? How they can make it better? Those two came up with the claw practicing their scenes in someone's house. They could be out doing anything anywhere but they're at home channelling their time into this. However goofy that claw might end up looking, I can't think of a better outcome than knowing they're doing that."

There is trust within the group involved in willingness to share, as honest and personal engagement is considered crucial for participants to progress in the programme and they are constantly encouraged to work on a personal level. Two-thirds of the 2015 interviewees claimed that the programme was helping them to develop trust through their peer community. One shared:

"I can believe in and trust these people. They don't laugh at me when I say something I think is stupid or ignore my ideas."

This is consistently reiterated throughout historical feedback with post-performance evaluations claiming development of 'trust', 'belief' and an enjoyment of 'speaking with people around me'. Participants are taught by example how to respond to personal revelations or obscure ideas appropriately and respectfully, and undertake other's critique and ideas for self-improvement. The programme does not claim that this process makes every participant an instantly model citizen, but they have ample opportunity to develop transferrable skills and make better choices independently. It is difficult to establish whether these changes are permanent, particularly in relation to juveniles due to their limited traceability. However, in terms of skill equipment and utilisation during their time on the programme, participants not only claim to have acquired abilities but also demonstrate these skills well in practice.

\section{Conclusions}

The programme considered in this article demonstrates the potential positive outcomes a Shakespeare-based approach could have for the rehabilitation of juvenile offenders. Though not all participants profess to love acting or Shakespeare, all claim to have learned from the programme, with most highlighting improvements in self-confidence, self-respect, feeling valued and the ability to understand the impact of their actions. Framed through reflection and application to real life, participants report that this programme has the potential to change participant perceptions and behaviours. Participants are intentionally given an opportunity through Shakespeare to explore personal and social issues, develop transferrable skills and feel that their contribution is valued.

Participants are by no means made perfect through this process, which again is important to note. The founders of the project explicitly said this project alone would not permanently fix them, and the intention was never to do so. Individual people cannot be simply fixed by engaging for 10 weeks in a Shakespeare play and discussions surrounding it. However, what they do is leave the group with 
the skills through which they can make better choices, communicate and express themselves and engage in positive activity. Through this they are equipped with the personal skills to consider their actions and with this may choose to make better future decisions. Although they cannot always track the progress of these participants, there are some encouraging examples of where the programme may have diverted an entire life trajectory.

Ex-participants have recurrently praised the programme, and one particular reoffender begged the court to send him back to the programme as he wanted to take full advantage, as he realised he had wasted much of the first time only engaging fully in the later stages. This individual went back on a one strike basis and served as an asset and ambassador for the group, undertaking a self-appointed mentorship role and successfully completing the programme for a second time. The programme actively does not exclude participants unless they absolutely have to, an approach that the current British education system does not always espouse. This programme offers participants the opportunity to value themselves and demonstrate to wider society that they are capable of more than their criminal history might imply. Although there is a clear agenda underpinning the delivery of this project, and participants are inevitably scaffolded towards drawing intentional positive conclusions, the project works hard to equip participants with the skills and belief that they can and are making positive decisions and changes independently and by choice.

Though this programme cannot profess to resolve all criminal behaviours, it offers crucial skills equipment opportunities in terms of confidence and commitment. The practices work to scaffold participants into developing empathy, finding means of self-expression and offer them new lenses through which to see themselves as part of their wider community, whilst still offering independence and collaboration as far as possible. Participants consistently report feeling valued, able to trust others and feel pride in their achievements, a feeling they desire to replicate. Though Shakespeare may not be the only applicable text to achieve these outcomes, this particular programme uses Shakespeare well to this effect. Shakespeare is not an inoculation or miracle cure against criminal behaviours, but he can be considered as a subject matter that can be used to springboard broader discussions, new experiences and facilitate the development of new ideas. For this reason, this paper would recommend a consideration of such an approach. Education and skills development is critical in reducing reoffending and this approach may be one way through which education can be used to rehabilitate participants and change their life trajectories, in turn positively impacting upon society at large.

Note 1 : Earned release scheme (Conservative Party 2015) is an educational initiative proposed by Michael Gove whereby upon successful completion of an examination based in-house prison education course prisoners could earn benefits such as earlier release than their initial sentence.

\section{Acknowledgements}

This research was supported by the Department of Education at the University of York; The Derwent College Development Award; and A Santander Gold International Connections Award.

\section{Funding}

This research was supported by the Department of Education at the University of York; The Derwent College Development Award; and A Santander Gold International Connections Award.

\section{Notes on contributor}

Laura Louise Nicklin is a doctoral researcher and seminar tutor in the Department of Education at The University of York. Due to be completed in 2017, her wider doctoral research project is a multi- 
sited ethnographic exploration of Shakespeare-focussed and performance-based programming implemented as both adult and juvenile criminal rehabilitation in the United States of America. She previously gained her BA (Hons) Language and Literature in Education from The University of York in 2012, followed by her MA in Shakespeare and Education at The Shakespeare Institute, University of Birmingham in 2013. She is also the co-convenor for the British Education Research Association's "Arts-Based Educational Research" special interest group.

\section{References}

Armstrong, S., and B. Weaver. 2013. "Persistent Punishment: User Views of Short Prison Sentences." The Howard Journal of Criminal Justice 52: 285-305. doi:10.1111/hojo.12015.

Artello, K., H. Hayes, G. Muschert, and J. Spencer. 2015. "What Do We Do with Those Kids? A Critical Review of Current Responses to Juvenile Delinquency and an Alternative." Aggression and Violent Behaviour 24: 1-8. doi:10.1016/j. avb.2015.04.014.

Baim, C. 2004. "If All the Worlds a Stage, Why Did I Get the Worst Parts." In Theatre in Prison, edited by M. Balfour, 139-160. Bristol: Intellect Books. Balfour, M. 2004. Theatre in Prison. Bristol: Intellect Books.

Batiuk, M. E., P. Moke, and W. Rountree. 1997. "Crime and Rehabilitation: Correctional Education as an Agent of Change-A Research Note." Justice Quarterly 14: 167-180.

doi:10.1080/07418829700093261.

Berk, R. A., and P. H. Rossi. 1997. Just Punishments: Federal Guidelines and Public Views Compared. New York: Aldine De Gruyter.

Bielby, G., M. Judkins., L. O'Donnell., and T. McCrone. 2012. Review of the Curriculum and Qualification Need of Young People Who are at Risk of Disengagement. Slough: The NFER Research Programme.

Blacker, J., A. Watson, and A. R. Beech. 2008. "A Combined Drama-Based and CBT Approach to Working with Self Reported Anger Aggression." Criminal Behaviour and Mental Health 18 (2): 129137. doi:10.1002/(ISSN)1471-2857.

Brookes, S., and A. Mountford. 2002. The Geese Theatre Handbook: Drama with Offenders and People at Risk. Winchester: Waterside Press.

Burdett, L. 2003. "“All the Colours of the Wind" Shakespeare and the Primary Student." In Reimagining Shakespeare for Children and Young Adults, edited by N. Miller, 44-55. New York: Routledge.

Clegg, N., and C. Grayling., Ministry of Justice, and Deputy Prime Ministers Office. 2014. Young Criminals must be Punished, but Education is the Cure. Government Report. London: Ministry of Justice.

Coates, S. 2016. Title to Be Confirmed- Prison Education Review. Government Report. London: Ministry of Justice. Conservative Party. 2015. "Earned Release." UK Government. Accessed 21 October 2016. https://www.conservatives. com/ /media/Files/.../Earned\%20Release.ash

Cook, G. 2000. Language Play, Language Learning. Oxford: Oxford University Press.

Curtis, A. J. 2014. "Tracing the School-To-Prison Pipeline from Zero-Tolerance Policies to Juvenile Justice Dispositions." Georgetown Law Journal. 102 (4): 1251-1277. 
Doherty, P. 1997. "Engaging Students on the Margins in Educatoional Research." Emotional and Behavioural Difficulties 45-49. doi:10.1080/1363275970020307.

Etherton, M. 2009. "Child Rights Theatre for Development With Disadvantaged and Excluded Children In South Asia and Africa." In The Applied Theatre Reader, edited by T. Prentki and S. Preston, 345-353. New York: Routledge.

Etherton, M., and T. Prentki. 2006. "Drama for Change? Prove It! Impact Assessment in Applied Theatre." Research in Drama Education: The Journal of Applied Theatre and Performance 11 (2): 139-155. doi:10.1080/ 13569780600670718.

Farrington, D. P. 1999. "Predicting Persistant Young Offenders." In Juvenile Delinquency in the United States and the United Kingdom, edited by G. L. MacDowell and J. Smith, 3-21, London : Macmillan Press

Gilmour, M. 2015. "Background to the RSA Shakespeare Project." In Shakespeare for All: The Primary School: An Account Od the RSA 'Shakespeare', edited by M. Gilmour, xv-1. London: Bloomsbury.

Gove, M. 2015. Education in Prison: Written Statement. Press Release. London: UK Parliament.

Grayling, C. 2014. Transforming Youth Custody: Putting Education at the Heart of Detention. Government Report. London: Ministry of Justice.

Guerin, L., M. D. Otis, and D. Royse. 2013. "Increasing Alternative Sentencing in the Juvenile Justice System through a Partnership between Public Defenders and Social Workers." Journal of Forensic Science. 3 (3): 261-277.

Hayes, J., and C. Blunt. 2011. Making Prisons Work: Skills for Rehabilitation: Review of Offender Learning. London: Department for Business, Innovation and Skills.

James, E. 2016. "Bring Teach First Graduate Scheme to Prisons, Review to Recommend." The Guardian, April 4.

Jones, P. 2006. Drama as Therapy: Theatre as Living. London: Routledge.

Landy, R. J. 1994. Drama Therapy: Concepts, Theories and Practices. Illinois: Charles Thomas.

Marsh, K. 2008. "The Real Cost of Prison." The Guardian. July 28. Accessed May 18, 2016. https://www.theguardian.com/commentisfree/2008/jul/28/justice.prisonsandprobation

Ministry of Justice. 2012. The Pre-Custody Employment, Training and Education Status of Newly Sentenced Prisoners. Government Report. London: Ministry of Justice. Ministry of Justice.

2013a. Compendium of Re-Offending Statistics and Analysis. Governemnt Report. London: Ministry of Justice.

Ministry of Justice. 2013b. Transforming Rehabilitation: A Summary of Evidence on Reducing Reoffending. Government Report. London: Ministry of Justice.

Ministry of Justice. 2015. Proven Reoffending Statistics: July 2012 to June 2013. Government Report. London: Ministry of Justice.

Ministry of Justice. 2015. Review of Prison Education: Terms of Reference. Government Report. London: UK Parliament. 
Moon, M. M., J. L. Sundt, F. T. Cullen, and J. P. Wright. 2000. "Is Child Saving Dead? Public Support for Juvenile Rehabilitation." Crime and Delinquency 38-60. doi:10.1177/0011128700046001003.

National Audit Office. 2010. Managing Offenders on Short Custodial Sentences. London: The Stationary Office.

Neelands, J., and J. O'Hanlon. 2011. There is Some Soul of Good: An Action Centred Approach to Teaching Shakespeare in Schools. Cambridge: Cambridge University Press.

Nicholson, H. 2014. Applied Drama: The Gift of Theatre. Basingstoke: Palgrave Macmillan.

Ofsted. 2014. The Report of Her Magesty's Chief Inspector of Education; Children; Services and Skills 2013/14. Manchester: OFSTED.

Peacock, R., and A. Theron. 2007. "Identity Development of the Incarcerated Adolescent with Particular Reference to Prison Gang Membership." Acta Criminologica. 20(3): 61-74.

Prentki, T., and S. Preston. 2013. The Applied Theatre Reader. New York: Routledge.

Prison Reform Trust. 2015. Bromley Briefings Autumn 2015. London: Prison Reform Trust.

Roberts, J. V. 2011. "Chapter Three: Public Opinion and the Nature of Community Penalties." In Changing Attitudes to Punishment, edited by J. V. Roberts and M. Hough, 33-62. London: Routledge.

Sellman, E. 2009. "Lessons Learned: Student Voice at a School for Pupils Experiencing Social, Emotional and Behavioural Difficulties." Emotional and Behavioural Difficulties 14: 33-48. doi:10.1080/13632750802655687.

Stephenson, M. 2009. Young People and Offending; Education, Youth Justice and Social Inclusion. London: Routledge.

The Royal Shakespeare Company. 2008. Stand Up For Shakespeare: A Manifesto for Shakespeare in Schools. Stratfordupon-Avon: RSC.

Travis, A. 2015. "Michael Gove to Call for Prisoners Who Study Hard to Get Early Release." The Guardian, July 17.

Uggen, C., and S. Wakefield. 2005. "Young Adults Re-Entering the Community from the Criminal Justice System." On Your Own without a Net:The Transition into Adulthood for Vulnerable Populations. 95 (3): 114-144.

Watson, A. 2013. "Lift Your Mask': Geese Theatre Company In Performance." In The Applied Theatre Reader, edited by T. Prentki and S. Preston, 47-54. New York: Routledge.

Winston, J. 2015. Transforming the Teaching of Shakespeare with the Royal Shakespeare Company. London: Bloomsbury.

Wood, W. R. 2011. "Correcting Community Service: From Work Crews to Community Work in a Juvenile Court." Justice Quarterly. 29 (5):1-28. 